\title{
PROPOSTA PARA REDUÇÃO DO ESCOAMENTO SUPERFICIAL DAS ÁGUAS PLUVIAIS EM SEROPÉDICA-RJ
}

\author{
Jackson Cleiton Feitosa Carvalho ${ }^{1}$
}

Vinicius Perrut dos Santos ${ }^{2}$

\begin{abstract}
RESUMO
Vários dos estudos hidrológicos apontam para o reaproveitamento das águas pluviais e para os danos causados nas superfícies por onde passa, principalmente quando o excesso de água passa pela cidade causando transtornos como alagamentos, erosão do solo, contaminação, e consequentemente engarrafamentos no trânsito de automóveis, poluição das águas, escorregamentos em encostas e outros. Neste contexto, novos conceitos de gerenciamento das águas provenientes do escoamento superficial em meio urbano vêm sendo aplicados e desenvolvidos em algumas cidades do mundo, nos últimos anos. O presente trabalho trata-se de uma proposta de metodologia e projeto para destinação final das águas de escoamento superficial. $O$ estudo foi proposto para a cidade de Seropédica, e foi considerado para a execução do projeto o tipo de solo, dados climáticos, uso do solo urbano, vegetação e topografia, como base para soluções pontuais de baixo custo com o objetivo de eliminar os alagamentos formados nos períodos de chuva.
\end{abstract}

PALAVRAS-CHAVE: Alagamentos urbanos. Drenagem de águas pluviais. Gestão ambiental urbana

\section{PROPOSAL FOR REDUCTION OF SURFACE FLOW OF PLUVIAL WATER IN SEROPÉDICA-RJ}

\footnotetext{
1 Graduando do Curso de Arquitetura e Urbanismo, UFRRJ. E-mail. jacksoncarvalho@outlook.com

${ }^{2}$ Engenheiro Agrimensor, Mestrando no PPG Desenvolvimento Territorial e Políticas Públicas, UFRRJ. E-mail. viniciusperrut@yahoo.com.br

${ }^{3}$ Arquiteta Professora Adjunto III do Curso de Arquitetura e Urbanismo e do PPG em

Desenvolvimento Territorial e Políticas Públicas, UFRRJ. schueler.a@gmail.com.
} 


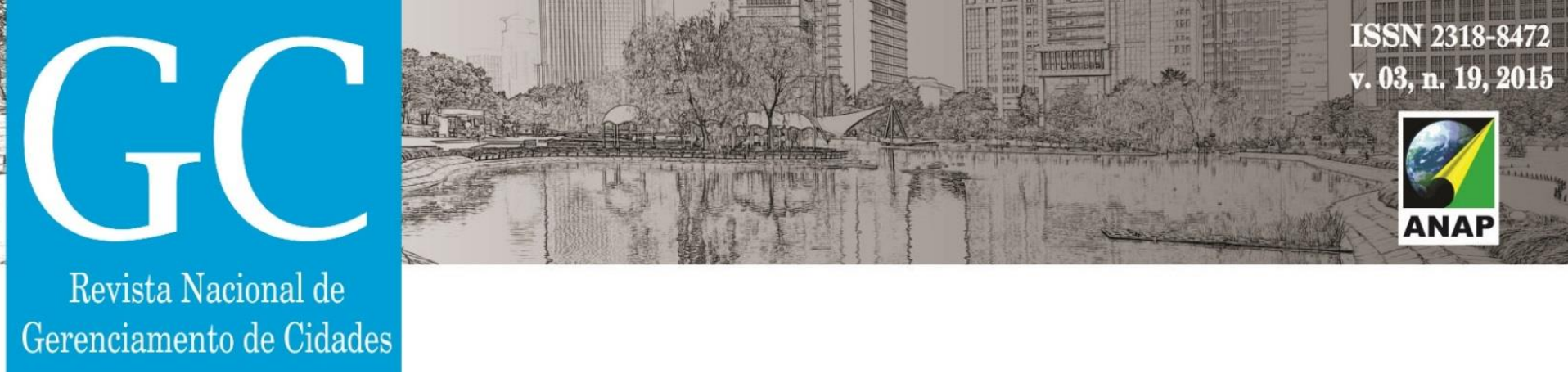

\begin{abstract}
Several of the hydrological studies point to the reuse of rainwater and to damage the surfaces where, especially when excess water goes through town causing disorders as flash floods, soil erosion, contamination, and therefore traffic jams in traffic, water pollution, landsliding in hillsides and others. In this context, new concepts of water management from the runoff in urban areas have been applied and developed in some cities around the world in recent years. The present work deals with a proposal of methodology and project for final disposal of runoff water. The study was proposed for the city of Seropédica, and was considered for the implementation of the type of soil, climate data, urban land use, vegetation and topography, as the basis for low-cost point solutions in order to eliminate the flooding formed during periods of rain.
\end{abstract}

\title{
PROPUESTA PARA LA REDUCCIÓN DE LA SUPERFICIE DE FLUJO DE AGUA PLUVIAL EN SEROPÉDICA-RJ
}

\begin{abstract}
RESUMEN
Varios de los estudios hidrológicos señalan a la reutilización del agua de lluvia y dañar las superficies, especialmente cuando exceso de agua va por la ciudad causando trastornos como inundaciones, erosión, contaminación del suelo y por lo tanto tráfico atascos de tráfico, contaminación del agua y deslizamientos de tierra en laderas. En este contexto, nuevos conceptos de gestión del agua de los escurrimientos en las zonas urbanas han sido aplicados y desarrollados en algunas ciudades alrededor del mundo en los últimos años. El presente trabajo aborda una propuesta de proyecto y metodología de disposición final del agua de escurrimiento. El estudio fue propuesto para la ciudad de Seropédica y era considerado para la aplicación del tipo de suelo, datos climáticos, urbano uso del suelo, vegetación y topografía, como la base para soluciones puntuales de bajo costo para eliminar la inundación formó durante los períodos de lluvia.
\end{abstract}

\section{INTRODUÇÃO}

A cidade de Seropédica, no Rio de Janeiro, como muitas outras cidades da região, sofre com extensos alagamentos em períodos de chuvas que muitas vezes perduram por todo o verão. O sistema de drenagem de águas pluviais, quando existe, em diversas ocasiões é desrespeitado, com interrupções por ocupação indevida do solo. As águas da chuva dificultam as atividades no meio urbano, causam transtornos de mobilidade, tornam o transito caótico, propiciam 


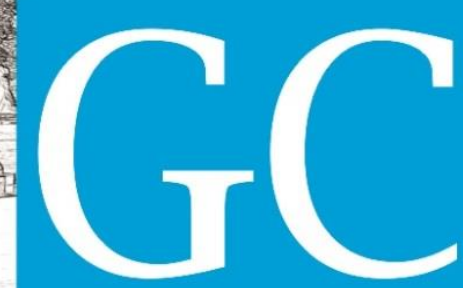

Revista Nacional de

Gerenciamento de Cidades

absorção da água da chuva, porém com rápida saturação. Abaixo da camada arenosa existe uma camada espessa de solo argiloso de baixa permeabilidade.

Quanto aos dados climáticos, segundo a série histórica cedida pelo INMET, Seropédica está localizado em regiões classificadas como de clima tropical quente (temperatura média superior a $18^{\circ} \mathrm{C}$ ), sub-quente (entre $18^{\circ}$ e $15^{\circ} \mathrm{C}$ ) e sub-tipo úmido (1 a 3 meses secos). A precipitação pluviométrica tem média anual que chega a $1.224,9 \mathrm{~mm}$, com os maiores valores ocorrendo no período de novembro a abril (meses mais quentes), com médias mensais variando entre 109,2 mm (abril) e 196,1 mm (janeiro). Nos demais meses, o índice médio obtido varia entre 30,7 mm e 93,6 $\mathrm{mm}$ (outubro).

A evaporação média anual obtida é de $1.352 \mathrm{~mm}$, o que supera a altura pluviométrica total. O maior valor médio foi obtido no mês de janeiro $(123 \mathrm{~mm})$, e o menor em abril $(91 \mathrm{~mm})$. O balanço hídrico apresenta-se positivo nos meses de janeiro a maio, e negativo entre maio e outubro. A figura 1 apresenta valores médios mensais de precipitação, temperatura e evapotranspiração.

Figura 1: Balanço hídrico mensal - calculado a partir de série histórica climática de $\mathbf{3 0}$ anos

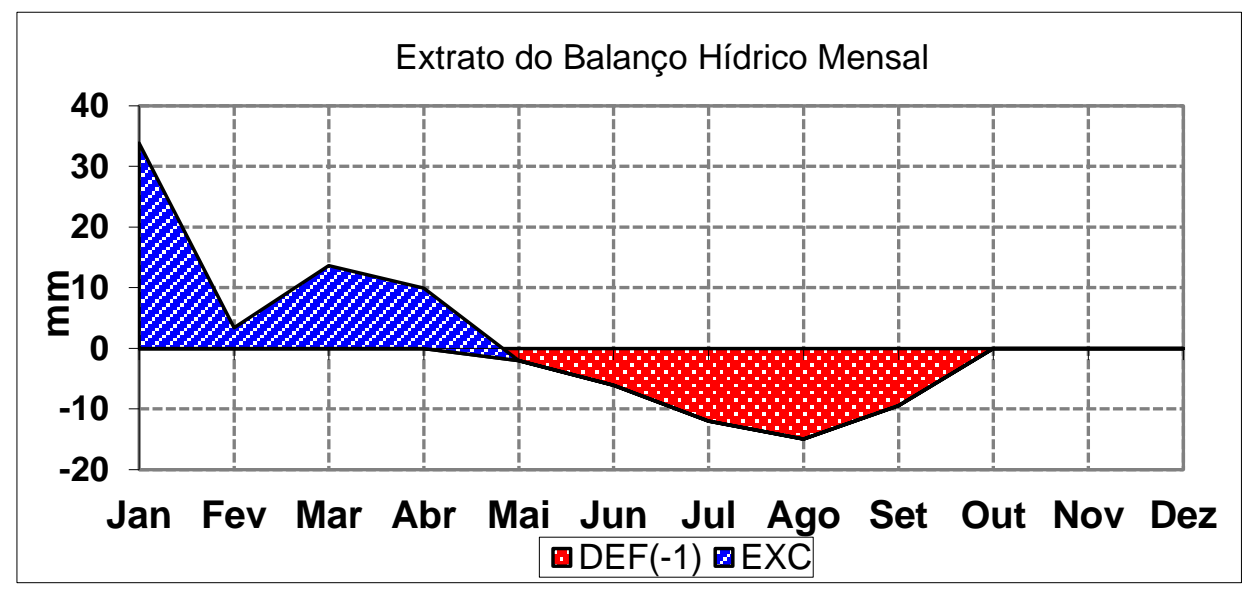

Fonte: INMET $1980-2010$. 


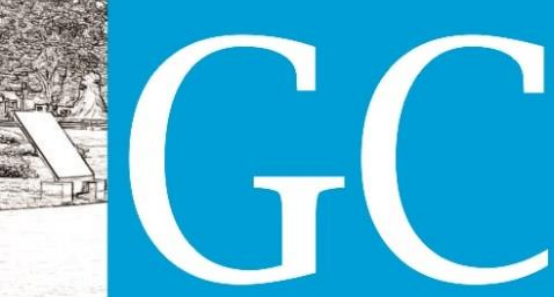

Revista Nacional de

Gerenciamento de Cidades

Foram identificados alguns pontos persistentes de alagamento que atrapalham o transito local e a dinâmica da cidade, principalmente por cortar a Rodovia BR 465, o que inviabiliza a passagem do transeunte nos períodos de chuva e torna o transito caótico. A Figura 2 mostra a localização das poças e da micro bacia usada como modelo de diagnóstico e intervenção urbana utilizando BMPs.

Figura 2: Relação tecido urbano e localização da bacia de estudo (em vermelho)

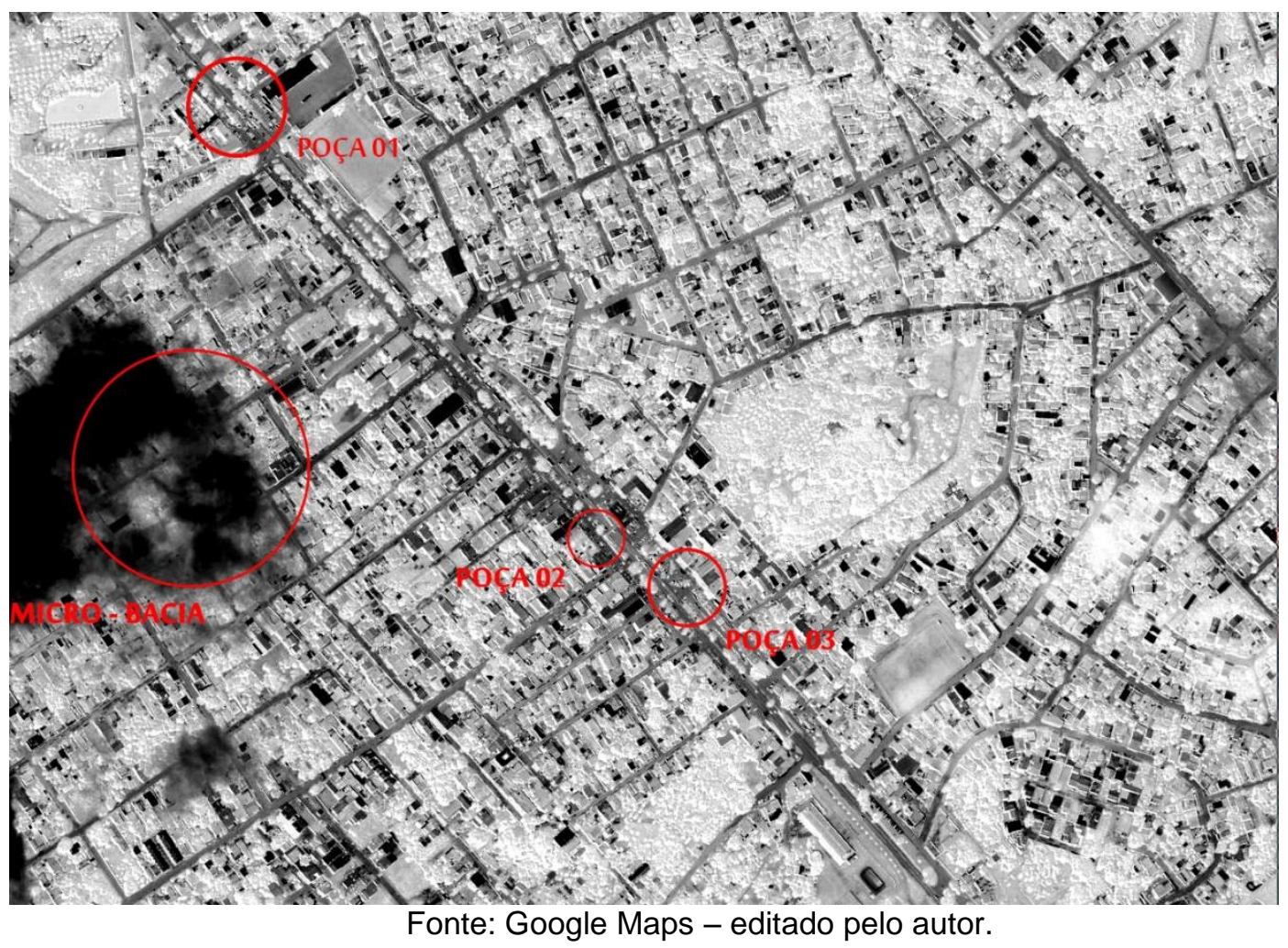

Foi mensurado a área das poças formadas (tabela 01), dentro do recorte correspondendo a rodovia BR 465, e a partir disto obtido seus respectivos volumes para o período de chuva mais intensa. Através do volume das poças d'água é possível dimensionar a área dos jardins de chuva, pois o espaço do jardim de chuva deve ser capaz de conter o volume das poças. 


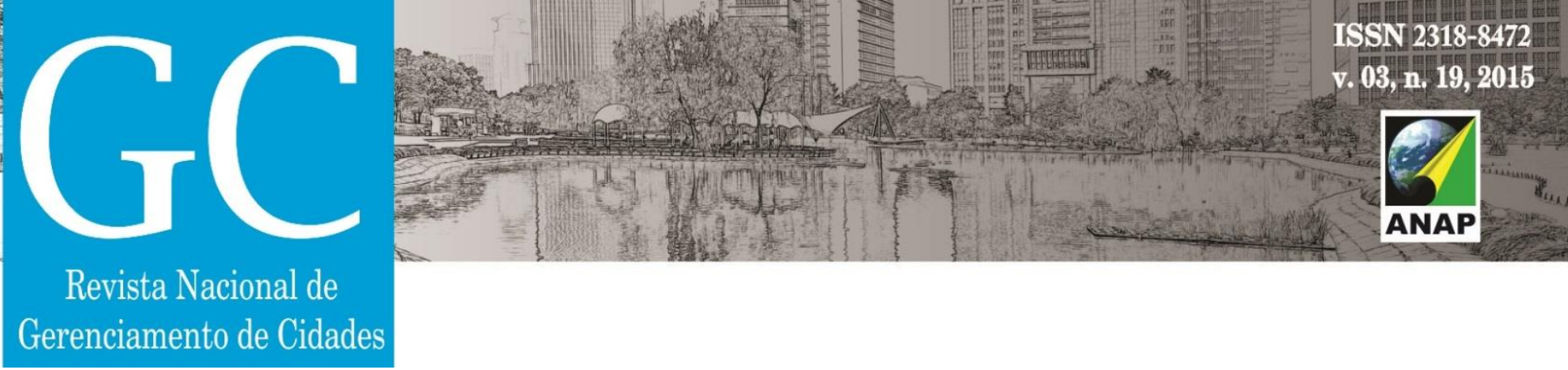

Tabela 01: Área das poças na BR 465

\begin{tabular}{ccc}
\hline & ÁREA $\left(\mathrm{m}^{2}\right)$ & VOLUME $\left(\mathrm{m}^{3}\right)$ para $196 \mathrm{~mm}$ \\
\hline Poça 01 & 385,85 & 75,6 \\
\hline Poça 02 & 64,02 & 12,5 \\
\hline Poça 03 & 238,56 & 46,7 \\
\hline
\end{tabular}

Fonte: Elaborado pelo autor.

Segundo Alejandro R. Dussaillant da Universidade do Chile trabalhando nos Estados Unidos no Estado de Wisconsin, ele demonstrou que o jardim de infiltração auxilia a recarga do aquífero subterrâneo de 15\% a 37\% (Dussaillant et all, 2004).

As plantas utilizadas no paisagismo cumprem a função de orientar o caminho das águas pluviais pelo solo sem causar os problemas de mobilidade e embelezando a paisagem, tornando o meio urbano mais agradável.

Ao pensar em como o transeunte é prejudicado pelo incomodo das poças pelo caminho, somada a dificuldade em atravessar a BR, foi necessário hierarquizar o desenho urbano, delimitando cada espaço de forma mais fluida possível (figura 3). 


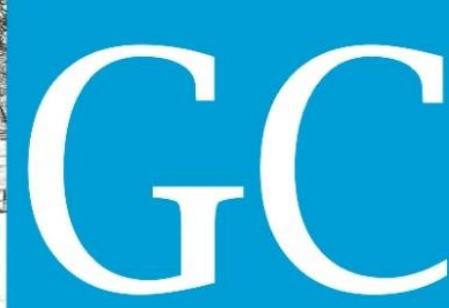

Revista Nacional de

Gerenciamento de Cidades

Figura 4: Plantas para plantio no jardim de chuva

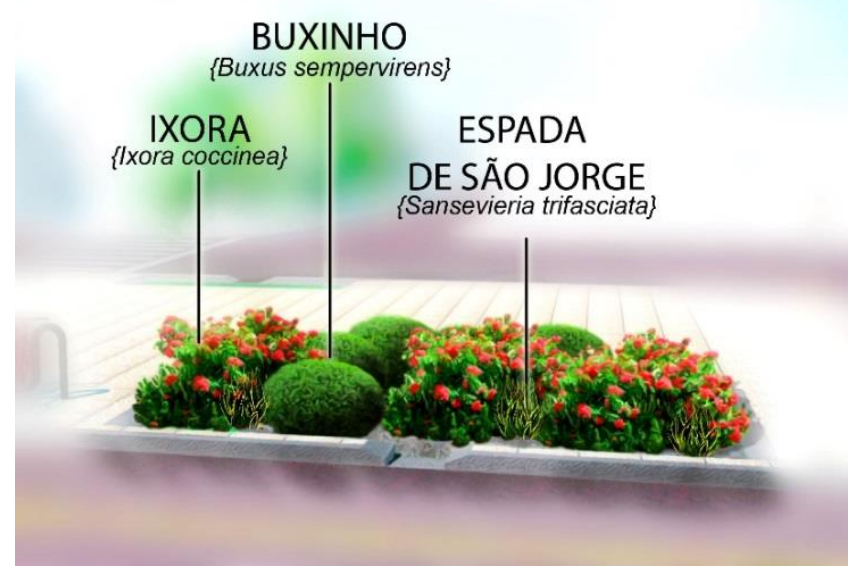

Fonte: Elaborado pelo autor

A área destinada para o jardim de chuva é preparada com materiais porosos, a fim de aumentar a infiltração da água no solo (figura 5), facilitando à drenagem natural, detendo a água em local apropriado, longe do caminho dos carros e transeuntes.

Figura 5: Detalhamento do jardim de infiltração

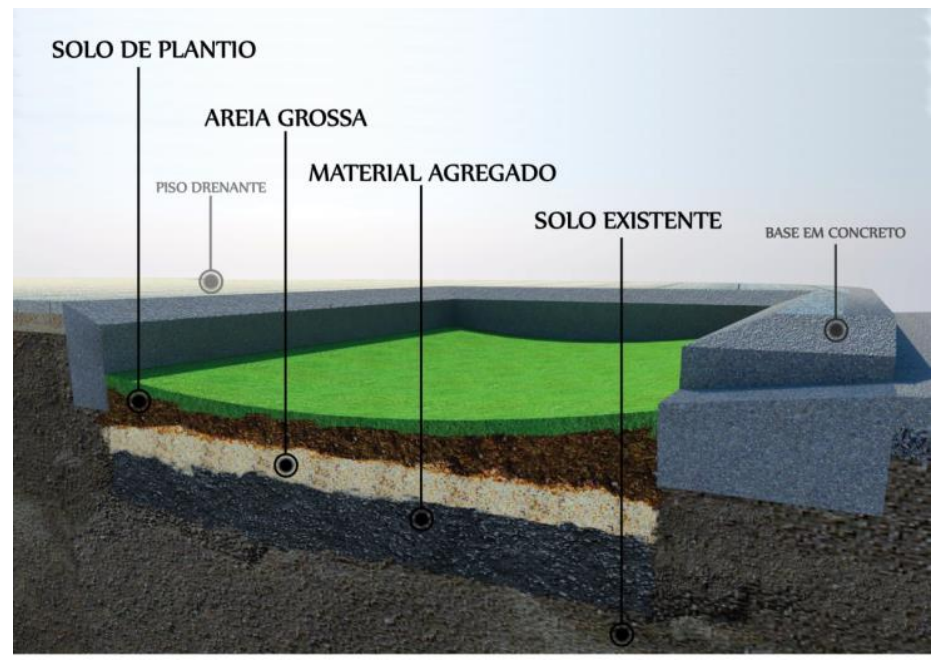

Fonte: Elaborado pelo autor. 


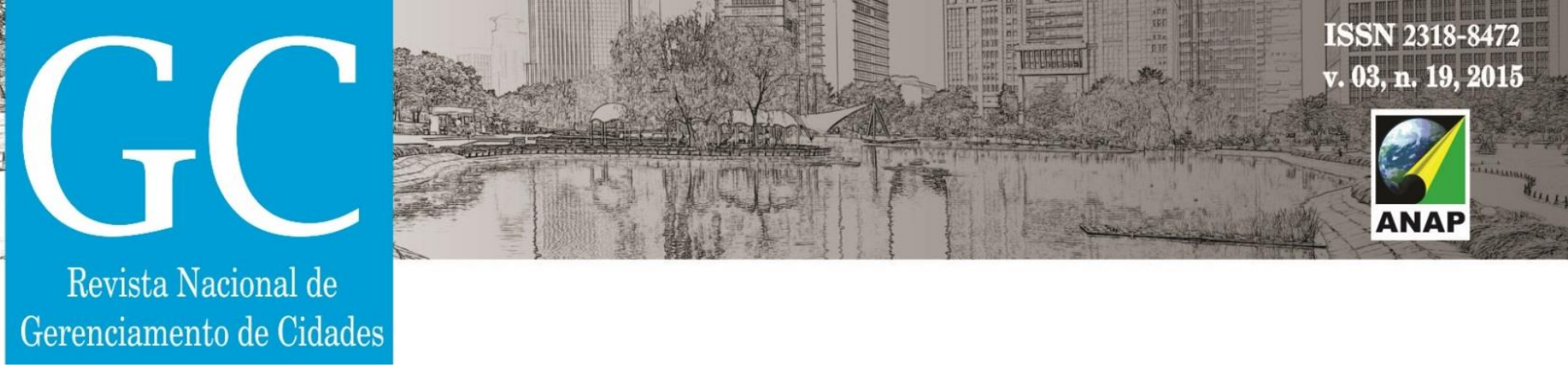

Em auxilio ao jardim de chuva, vale pontuar o uso de piso drenante em calçadas e estacionamentos, por garantir a eficiência da infiltração de água no solo, e possuir grande permeabilidade e alta resistência.

No lote urbano

Para fins de quantificação da melhoria no sistema de drenagem existente, foi selecionada uma sub-bacia localizada no tecido urbano composta por diversos lotes. A Figura 6 mostra a localização de diversas micro bacias e a localização da micro bacia selecionada, onde foi analisada e quantificada (Tabela 2) a área permeável.

Tabela 2: Área permeável e impermeável

\begin{tabular}{clll}
\hline ÁREA TOTAL $\left(\mathrm{m}^{2}\right)$ & ÁREA PERMEAVEL $\left(\mathrm{m}^{2}\right)$ & $\begin{array}{l}\text { ÁREA IMPERMEÁVEL } \\
\left(\mathrm{m}^{2}\right)\end{array}$ \\
& & 13844,60 \\
\hline PERCENTUAL & $100 \%$ & 11380,40 & $54,89 \%$ \\
\hline
\end{tabular}

Fonte: Elaborado pelo autor.

Figura 6: Bacia selecionada dentro do limite urbano

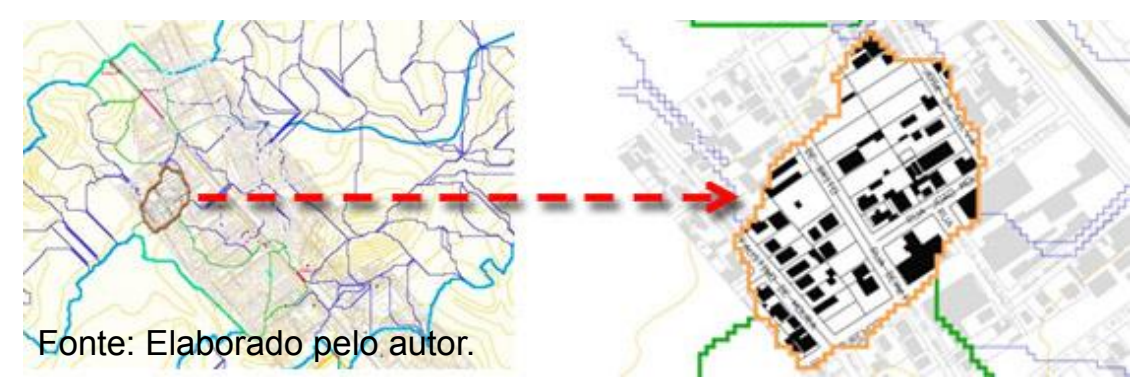




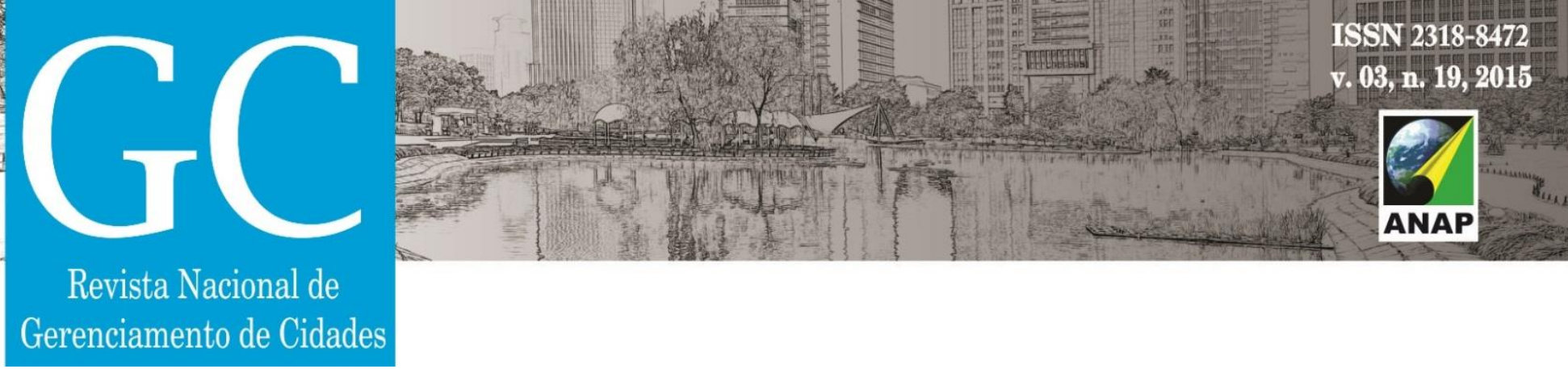

Figura 7: Mapa de permeabilidade (área permeável em verde, área impermeável em preto)

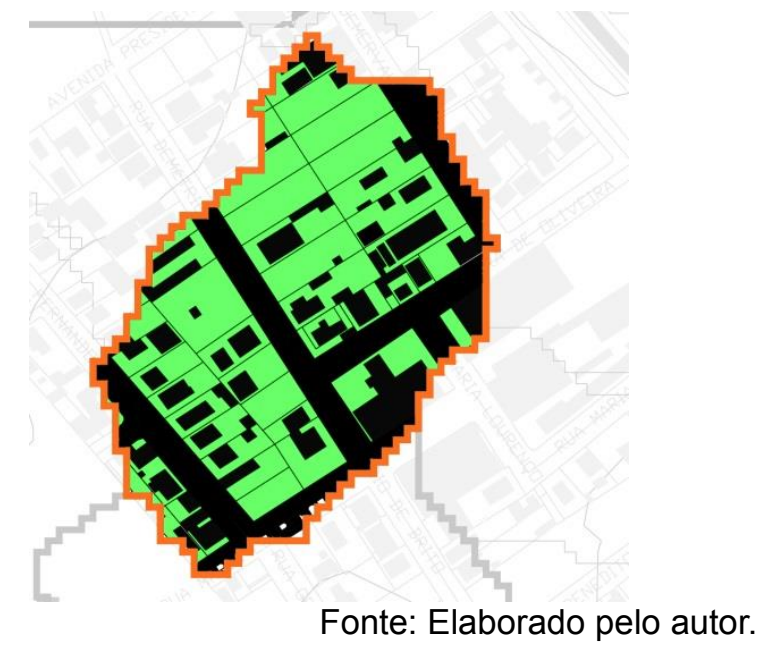

Nota-se que sobre nesta micro bacia (Figura 7), que a área impermeável é discretamente superior a área permeável. Essa característica da cobertura, somada a baixa permeabilidade do solo, constituem fatores fundamentais para que a sofra com recorrentes poças d'água após as chuvas.

Considerando que a área de cada lote é maior que $300 \mathrm{~m}^{2}$ e com base nas áreas permeáveis e localização dos lotes, o município pode adotar diretrizes como:

- Atualizar legislação regulamentando a taxa de ocupação dos lotes, e estabelecer uma taxa de permeabilidade variando de 20 a $30 \%$ da área total do lote;

- Adotar dispositivos de acumulação imediata de águas de chuva como reservatórios; esta ultima seria uma cota de acumulação por lote, sendo pré-estabelecido em detrimento da área total;

- Construção de jardins de chuva ao longo das calçadas;

- Adotar calçadas e sarjetas drenante. 
